\title{
pesquisa
}

MATTOS LM; MORETTI CL; CHITARRA AB; PRADO MET. 2007. Qualidade de alface crespa minimamente processada armazenada sob refrigeração em dois sistemas de embalagem. Horticultura Brasileira 25: 504-508.

\section{Qualidade de alface crespa minimamente processada armazenada sob refrigeração em dois sistemas de embalagem}

\author{
Leonora M Mattos ${ }^{1}$; Celso Luiz Moretti' ${ }^{1}$; Adimilson B Chitarra ${ }^{2}$; Mônica ET Prado ${ }^{2}$ \\ ${ }^{\text {I}}$ Embrapa Hortaliças, C. postal 218, 70359-970 Brasília-DF; ${ }^{2}$ UFLA, 3037, 37200-000 Lavras-MG; leonora@ cnph.embrapa.br
}

\section{RESUMO}

O processamento mínimo acelera a perda de qualidade, reduz a vida de prateleira e modifica os atributos sensoriais de frutas e hortaliças. A alface minimamente processada sofre ainda o efeito do escurecimento enzimático resultante da descompartimentação de enzimas e seus substratos. Neste trabalho, avaliou-se a qualidade química, física e bioquímica de alface crespa minimamente processada e armazenada sob refrigeração em dois sistemas de embalagem. A alface cv. Verônica foi colhida em campos de produção comercial em Brasília, DF e processada nas formas de folha inteira e em tiras de $5 \mathrm{~mm}$. O material processado foi acondicionado em filmes de polipropileno e polietileno de baixa densidade e armazenado a $5^{\circ} \mathrm{C}$ durante 14 dias. A cada dois dias, as alfaces foram avaliadas quanto à acidez titulável, cor $\left(\mathrm{L}^{*} \mathrm{a} * \mathrm{~b}^{*}\right)$ e atividade das enzimas polifenoloxidase e peroxidase. A atividade tanto da polifenoloxidase como da peroxidase foi maior para o material processado como tiras de $5 \mathrm{~mm}$, quando comparado à alface processada como folha inteira. A alface processada como tiras de $5 \mathrm{~mm}$ apresentou maior escurecimento enzimático, menor brilho e menores teores de ácidos orgânicos para as duas embalagens estudadas.

Palavras-chave: Lactuca sativa L., polifenoloxidase, peroxidase, processamento mínimo, cor, acidez titulável.

\begin{abstract}
Quality of fresh-cut crisphead lettuce stored under refrigeration and two packaging systems

Minimal processing usually causes quality loss, reduces shelflife, and promotes sensory attributes alterations. The occurrence of browning in the midrib of fresh-cut lettuce is commonly observed and is associated with cell tissue disrupture, putting in contact enzymes and their respective substrates. Chemical, physical, and biochemical quality of fresh-cut crisphead lettuce stored under refrigeration and two different packaging systems were evaluated in the present work. Lettuce cv. Verônica was harvested in commercial fields in Brasilia, Brazil, and was minimally processed as whole leaves and $5 \mathrm{~mm}$ strips. Fresh-cut lettuce was then packed into polypropylene and low density polyethylene plastic films and was stored at $5^{\circ} \mathrm{C}$ during 14 days. Every two days processed material was evaluated for titratable acidity, color $\left(L^{*} a * b *\right)$ and polyphenoloxidase and peroxidase enzymes activity. Lettuce processed as whole leaves showed higher brightness $\left(\mathrm{L}^{*}\right)$ when compared to the material sliced at $5 \mathrm{~mm}$, for both the packaging systems studied. Both polyphenoloxidase and peroxidase activities were higher for fresh-cut lettuce sliced at $5 \mathrm{~mm}$ when compared to whole leaves. Lettuce processed as $5 \mathrm{~mm}$ strips had the highest enzymatic browning, lowest brightness and organic acid content for both the packaging systems studied.
\end{abstract}

Keywords: Lactuca sativa L., polyphenoloxidase, peroxidase, freshcut, color, titratable acidity.

(Recebido para publicação em 16 de julho de 2007; aceito em 29 de novembro de 2007)

\begin{abstract}
A $\mathrm{s}$ hortaliças minimamente processadas têm-se tornado cada vez mais populares, tanto em nível institucional como doméstico, pela conveniência, aliada à elevada qualidade sensorial e pelos benefícios de um produto seguro (Schlimme, 1995; Cantwell, 2000).

Por tratar-se de um produto injuriado, principalmente devido ao corte, a vida de prateleira é reduzida em relação ao produto não processado (Cantwell, 1992), apresentando comportamento fisiológico de tecidos vegetais submetidos a condições de estresse (Brecht et al., 2007). O processamento mínimo de hortaliças pode ocasionar a descompartimentação de enzimas e seus
\end{abstract}

substratos, resultando no aumento da atividade das enzimas responsáveis pelo escurecimento e no desenvolvimento de sabores e odores desagradáveis, da taxa respiratória, da evolução de etileno e de compostos fenólicos solúveis e totais (Ahvenainen, 1996; Avena-Bustillos et al., 1993; Brecht et al., 2007; Chitarra \& Chitarra, 2007; Kim et al., 1994; Nicoli et al., 1994; Priepke et al., 1976; Rolle \& Chism, 1987).

O escurecimento enzimático em hortaliças é considerado uma das mais importantes desordens e pode ser facilmente detectada pelos consumidores pelas evidências na comercialização. A alface é uma das hortaliças mais estudadas por apresentar maior sensibilidade a essa desordem (Saltveit, 2000; Degl'Innocenti et al., 2007), que na maioria das vezes é resultado da ação de enzimas como a polifenoloxidase e a peroxidase.

As duas enzimas catalisam mais de uma reação e agem sobre uma gama de substratos, podendo levar à descoloração, à formação de compostos aromáticos indesejáveis e perdas nutricionais, além de ocasionar o escurecimento dos tecidos. As ações das enzimas peroxidase (POD) e polifenoloxidase (PFO) afetam principalmente a capacidade de hortaliças manterem suas características sensoriais, como cor e sabor 
(Burnette, 1977; Vamos-Vigyazo, 1981). A atividade da peroxidase pode resultar em reações oxidativas que envolvem doadores de hidrogênio em alimentos (Padiglia et al., 1995). A inativação dessa enzima, que está associada à formação de odores indesejáveis em frutas e hortaliças, é considerada necessária para minimizar o risco de deterioração (Ponce et al., 2004). De acordo com Lamikanra \& Watson (2001), mudanças oxidativas e na coloração, decorrentes da atuação da PFO são resultantes das atividades da creolase e catecolase.

Como os consumidores preferem produtos frescos que são preparados para consumo sem perda dos atributos de qualidade como textura, sabor, aroma e aparência, vários estudos para aumentar a vida de prateleira de hortaliças minimamente processadas têm sido focados em métodos alternativos para inibir o escurecimento (FDA, 2001).

Este trabalho teve como objetivo avaliar o efeito de dois tipos de corte (folhas inteiras e tiras) e de duas embalagens (filmes de polipropileno e polietileno) na conservação de alface crespa minimamente processada armazenada sob refrigeração.

\section{MATERIAL E MÉTODOS}

Cabeças de alface cv. Verônica foram colhidas em campos de produção comercial em Brasília, levadas ao laboratório de pós-colheita da Embrapa Hortaliças, onde foram selecionadas e as folhas foram lavadas em água corrente. Logo após o material foi minimamente processado nas formas de folhas inteiras e tiras no sentido transversal com espessura de $5 \pm 1 \mathrm{~mm}$ em um processador de vegetais (marca 'Robot Coupe CL 50'), previamente higienizado com solução de hipoclorito de sódio (200 ppm de cloro ativo). O material processado foi enxaguado, sanitizado em água com $150 \mathrm{mg} \mathrm{L}^{-1} \mathrm{de}$ cloro ativo a $5^{\circ} \mathrm{C}$, por 5 minutos e enxaguado em água potável a $5 \pm 1^{\circ} \mathrm{C}$ e centrifugado, por 3 minutos, a $800 \times \mathrm{x}$.

As alfaces minimamente processadas foram acondicionadas em filmes de polipropileno e polietileno de baixa densidade e seladas com o auxílio de uma

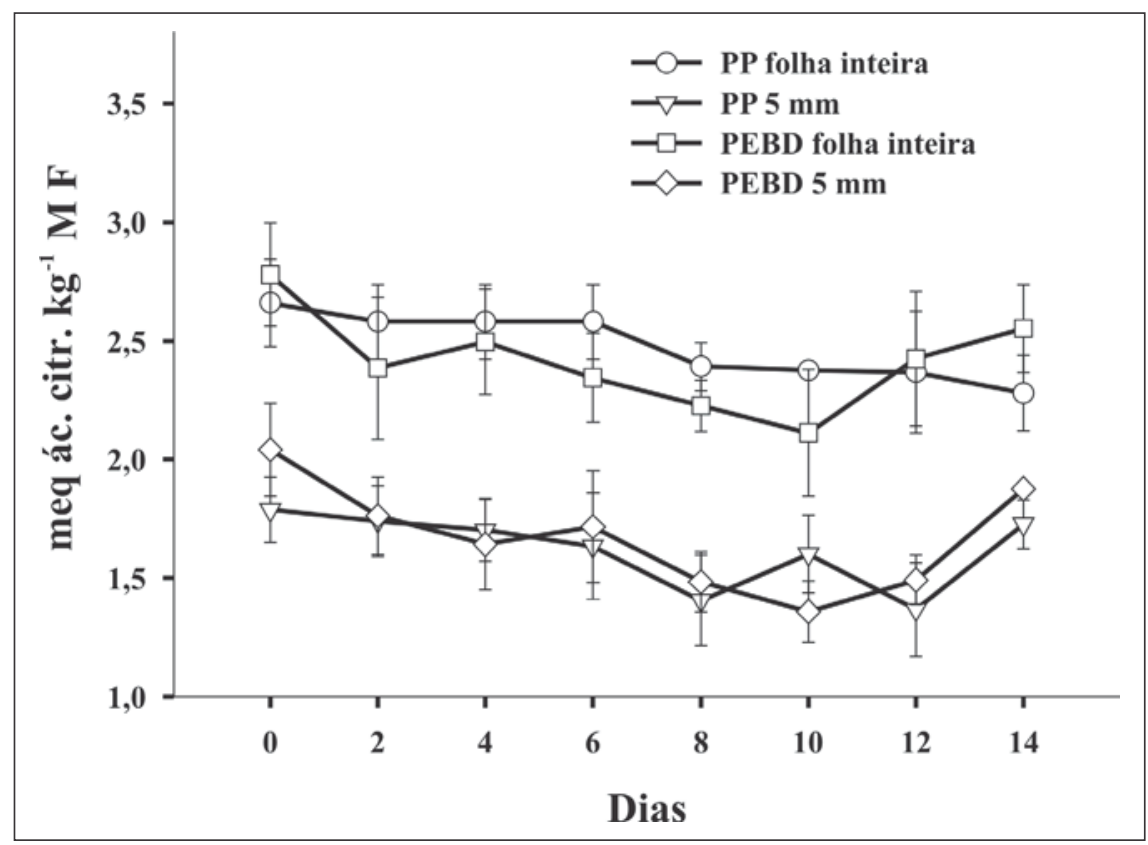

Figura 1. Acidez titulável em alfaces minimamente processadas como folhas inteiras e tiras de $5 \mathrm{~mm}$, armazenadas a $5^{\circ} \mathrm{C}$ em embalagens de PEBD e PP. Barras verticais representam \pm o desvio-padrão da média. $\mathrm{PEBD}=$ Polietileno de baixa densidade. $\mathrm{PP}=$ Polipropileno. MF = Matéria-fresca. (Titratable acidity of fresh-cut lettuce processed as whole leaves and 5 mm strips stored at $5{ }^{\circ} \mathrm{C}$ in LDPE and PP. Vertical bars represent \pm standard deviation. LDPE = Low density polyethylene. $\mathrm{PP}=$ Polypropylene). Brasília, Embrapa Hortaliças, 2006.

seladora comercial (Selovac 200B), em porções de $200 \mathrm{~g}$. O produto embalado foi armazenado a $5^{\circ} \mathrm{C}, 85 \pm 5 \%$ de umidade relativa durante 14 dias.

A cada dois dias, as alfaces foram avaliadas para acidez titulável, cor $\left(L^{*} a * b^{*}\right)$ e atividade enzimática da polifenoloxidase e da peroxidase. A acidez total titulável foi determinada segundo metodologia descrita por Moretti et al. (1998) e os resultados foram expressos em miliequivalentes de ácido cítrico por kg de tecido fresco. A cor das amostras foi determinada usando-se um colorímetro (Minolta, modelo CR200B), $L, a, b$ - da escala Hunter (CTL*a* $b^{*}$ ), em que o eixo $a$ representa a cromaticidade entre as cores verde e vermelha, o eixo $b$, entre o amarelo e o azul e o $L$, o brilho. A atividade das enzimas polifenoloxidase e peroxidase foi determinada segundo o método descrito por Hemeda \& Klein (1990), sendo o extrato lido a $395 \mathrm{~nm}$ para POF e a $470 \mathrm{~nm}$ para POD. Os resultados das atividades de polifenoloxidase e peroxidase foram expressos em $\mathrm{U} \mathrm{g}^{-1} \mathrm{~min}^{-1}$.

$\mathrm{O}$ delineamento experimental empregado foi inteiramente casualizado com 32 tratamentos provenientes de um arranjo fatorial $2 \times 2 \times 8$ (2 tipos de processamento, 2 tipos de embalagem e 8 tempos de amostragem), com 4 repetições $(n=200 \mathrm{~g})$. Os dados foram submetidos à análise de variância e as médias foram comparadas pelo teste de diferença mínima significativa $(\mathrm{p} \leq 0,05)$. Diferenças entre dois tratamentos iguais ou maiores do que a soma de dois desvios-padrões foram sempre consideradas significativas ao nível de 5\% de probabilidade (Shamaila et al., 1992).

\section{RESULTADOS E DISCUSSÃO}

Observou-se tendência de redução do teor de ácidos orgânicos durante o período experimental tanto na alface minimamente processada na forma de folhas inteiras quanto a $5 \mathrm{~mm}$ armazenadas nas duas embalagens estudadas (Figura 1).

O teor de ácidos orgânicos da alface minimamente processada na forma de folha inteira, nas duas embalagens estudadas, foi sistematicamente maior do que as tiras a $5 \mathrm{~mm}$ durante todo o período experimental. No último dia de armazenamento, verificou-se que a acidez titulável da alface inteira, armaze- 


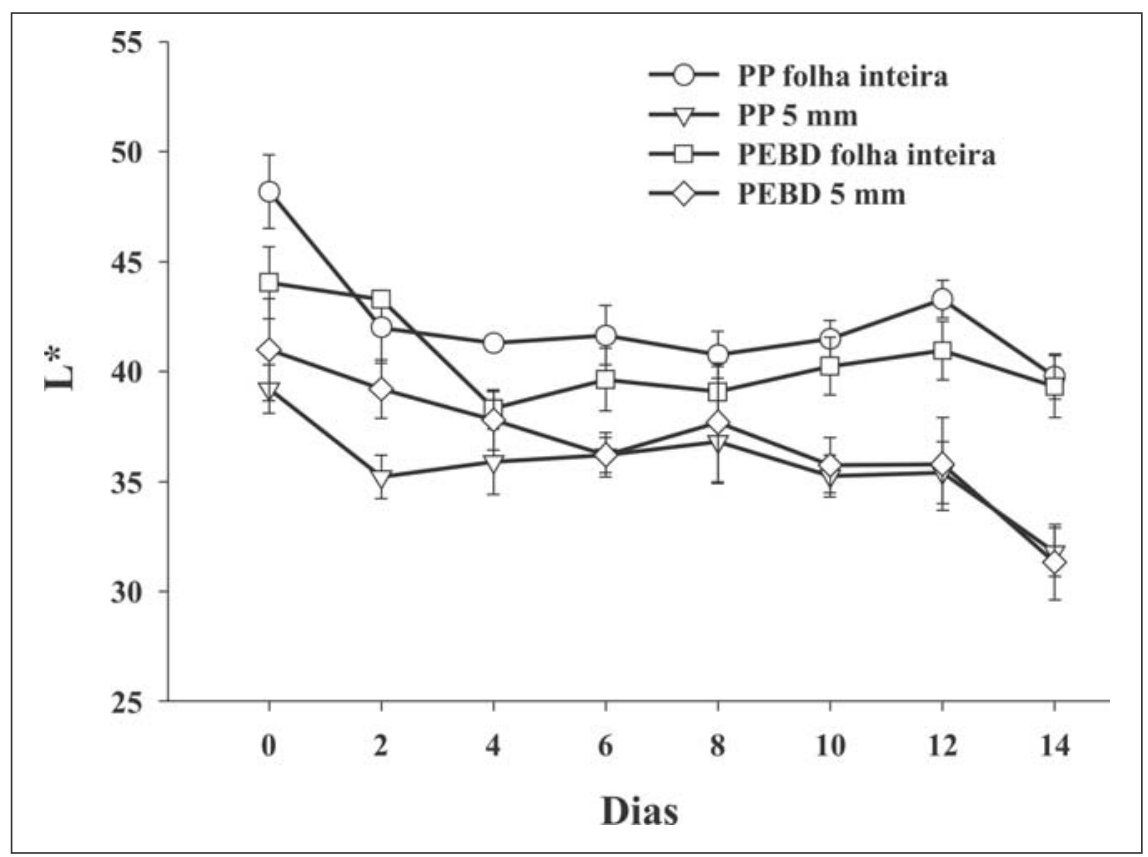

Figura 2. Brilho $\left(\mathrm{L}^{*}\right)$ de alfaces minimamente processadas como folhas inteiras e tiras de 5 $\mathrm{mm}$, armazenadas a $5{ }^{\circ} \mathrm{C}$ em embalagens de PEBD e PP. Barras verticais representam \pm 0 desvio-padrão da média. $\mathrm{PEBD}=$ Polietileno de baixa densidade $\mathrm{PP}=$ Polipropileno . (Brightness $\left(\mathrm{L}^{*}\right)$ of fresh-cut lettuce processed as whole leaves and $5 \mathrm{~mm}$ strips stored at 5 ${ }^{\circ} \mathrm{C}$ in LDPE and PP. Vertical bars represent \pm standard deviation. LDPE $=$ Low density polyethylene. $\mathrm{PP}=$ Polypropylene). Brasília, Embrapa Hortaliças, 2006.

nada em embalagem de PEBD, era cerca de $42 \%$ maior do que o material processado em tiras de $5 \mathrm{~mm}$ e armazenado na mesma embalagem. De maneira similar, observou-se que o teor de ácidos orgânicos na alface processada como folha inteira era ao redor de $35 \%$ maior do que das folhas minimamente processadas a $5 \mathrm{~mm}$, quando se avaliou o material embalado em polipropileno (Figura 1).

Acredita-se que o menor teor de ácidos orgânicos observado no material processado em forma de tiras, independente do tipo de embalagem utilizado, esteja relacionado com a maior atividade metabólica deste tratamento que sofreu maior estresse mecânico por ocasião do corte. Como os ácidos orgânicos também são substratos utilizados na atividade respiratória, a alface processada em tiras apresentou menor teor de ácidos orgânicos ao final do período experimental.

O estresse mecânico está associado à elevação do $\mathrm{pH}$ e conseqüente redução no teor de ácidos orgânicos. Moretti et al. (1998) verificaram que tomates que não sofreram estresse mecânico possuíam maior teor de ácidos orgâni- cos. Acredita-se que a redução da acidez titulável em produtos minimamente processados seja uma consequiência do metabolismo normal do $\mathrm{CO}_{2}$ ou uma resposta do tecido ao neutralizar a acidez gerada pelo $\mathrm{CO}_{2}$ (Kader, 1986).

Observou-se que o brilho das alfaces minimamente processadas na forma de folhas inteiras apresentou valores superiores aos que os verificados para as folhas minimamente processadas a 5 $\mathrm{mm}$ (Figura 2). Verificou-se que, a partir do oitavo dia de armazenamento, as folhas inteiras de alface embaladas em filme de polietileno de baixa densidade apresentaram ligeira tendência de elevação do brilho, enquanto a alface minimamente processada na forma de tiras, na mesma embalagem, apresentou tendência de redução do brilho. Ao final do experimento, o brilho das folhas inteiras embaladas em PEBD era aproximadamente $45 \%$ maior do que as processadas em tiras (Figura 2).

Tendências similares foram verificadas para os materiais embalados em filme de polipropileno. A partir do décimo de armazenamento, as alfaces minimamente processadas na forma de folhas inteiras apresentaram tendência de aumento do brilho, ao passo que as processadas em tiras, na mesma embalagem, apresentaram tendência de redução do brilho. No $14^{\circ}$ dia de armazenamento, o brilho das alfaces minimamente processadas na forma de folhas inteiras era cerca de $30 \%$ maior ao das folhas processadas em tiras, (Figura 2). O menor brilho apresentado pelas alfaces cortadas em tiras, pode ser atribuído ao maior estresse mecânico sofrido pelos tecidos, propiciando o contato entre enzimas e substratos, levando ao escurecimento.

$\mathrm{O}$ escurecimento verificado em tecidos vegetais pode ser ocasionado tanto por processos não enzimáticos, os quais podem estar relacionados tanto com a degradação da vitamina C (Klein, 1987), quanto por processos enzimáticos que ocorrem por meio de reações oxidativas catalisadas por fenolases, como por exemplo, a PPO (Vaughn \& Duke, 1984; McEvily \& Iyengar, 1992; Schlimme, 1995).

Verificou-se que as alfaces minimamente processadas em tiras de $5 \mathrm{~mm}$ apresentaram maior atividade da enzima polifenoloxidase, independente do tipo de embalagem utilizada, do que o material processado como folhas inteiras durante os 14 dias de armazenamento (Figura 3). Na alface minimamente processada a $5 \mathrm{~mm}$ embalada tanto em filme de polietileno de baixa densidade quanto em polipropileno, verificou-se atividade da polifenoloxidase sistematicamente maior do que o material processado como folha inteira. A diferença na atividade da enzima foi significativamente maior no material minimamente processado a $5 \mathrm{~mm}$ em comparação ao material processado como folha inteira, para ambas as embalagens, nos primeiros 10 dias de armazenamento, porém após esse período, as diferenças entre as folhas processadas em tiras e as inteiras, em ambas as embalagens, não foi mais significativa (Figura 3).

A maior atividade da enzima polifenoloxidase nas alfaces minimamente processadas em tiras é uma consequiência do maior estresse mecânico sofrido pelo tecido nesse tratamento, o que contribuiu para a redução do brilho desses materiais, conforme observado anteriormente (Figura 2). Adicional- 
mente, a maior atividade da polifenoloxidase no material processado em tiras e embalado em filme de PEBD comparativamente ao mesmo material embalado em filme de PP, nos seis primeiros dias de armazenamento, pode ser explicada pela maior permeabilidade do polietileno de baixa densidade ao oxigênio, possibilitando que a enzima atuasse de forma mais efetiva na alface armazenada neste tipo de embalagem. Tal fenômeno também foi observado para as alfaces processadas como folhas inteiras, onde o material embalado em filme de PEBD apresentou maior atividade da enzima em comparação ao material embalado em filme de PP. Todavia, em função de o estresse, nesse caso, ser menor, a diferença foi significativa apenas nos dois primeiros dias de armazenamento (Figura 3).

As alterações observadas no presente experimento na alface minimamente processada são compatíveis com as diferentes alterações relatadas na literatura mundial, por diversos autores. Os estresses mecânicos associados ao processamento mínimo ocasionam a perda de integridade celular na superfície cortada, colocando em contato enzimas e seus substratos que até então estavam em compartimentos celulares separados. Os estresses sofridos contribuem ainda para a elevação da taxa respiratória, da evolução de etileno e para a formação de compostos fenólicos solúveis associados ao escurecimento dos tecidos (Ahvenainen, 1996; Brecht, 1995; Rolle \& Chism, 1987).

De maneira similar ao que foi observado para a polifenoloxidase, verificou-se que alfaces processadas em tiras apresentaram maior atividade da enzima peroxidase em comparação à alface processada como folhas inteiras (Figura 4). Logo após o processamento mínimo, verificou-se que a atividade da peroxidase era estatisticamente igual tanto para as folhas inteiras como para as processadas a $5 \mathrm{~mm}$. Observou-se, entretanto, que tal diferença tornou-se significativa a partir do segundo dia de armazenamento (Figura 4). Este resultado pode ser atribuído ao fato do estresse mecânico sofrido tanto pelo material processado a $5 \mathrm{~mm}$ quanto no processado como folhas inteiras ter in-

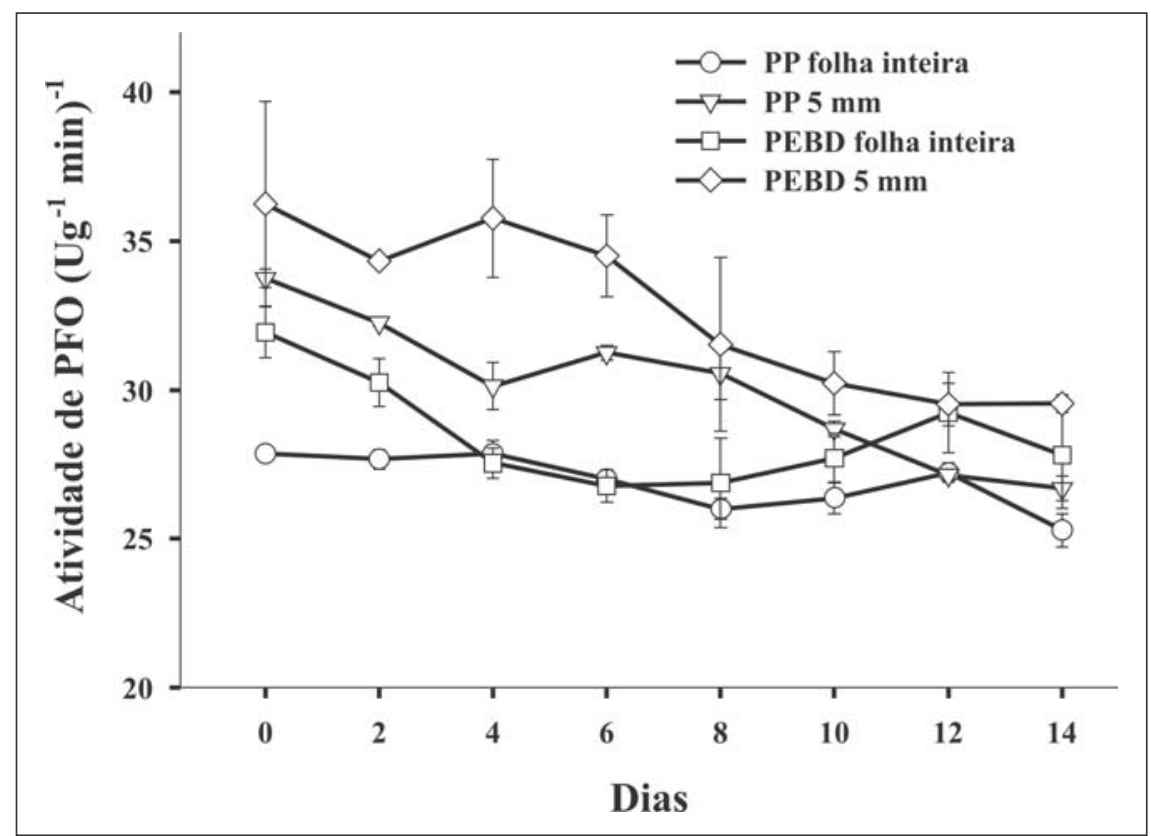

Figura 3. Atividade da polifenoloxidase em alfaces minimamente processadas como folhas inteiras e tiras de $5 \mathrm{~mm}$, armazenadas a $5^{\circ} \mathrm{C}$ em embalagens de PEBD e PP. Barras verticais representam \pm o desvio-padrão da média. $\mathrm{PEBD}=$ Polietileno de baixa densidade $\mathrm{PP}=$ Polipropileno. $\mathrm{PFO}=$ Polifenoloxidase. (Polyphenoloxidase activity of fresh-cut lettuce processed as whole leaves and $5 \mathrm{~mm}$ strips stored at $5^{\circ} \mathrm{C}$ in LDPE and PP. Vertical bars represent \pm standard deviation. $\mathrm{LDPE}=$ Low density polyethylene. $\mathrm{PP}=$ Polypropylene). Brasília, Embrapa Hortaliças, 2006.

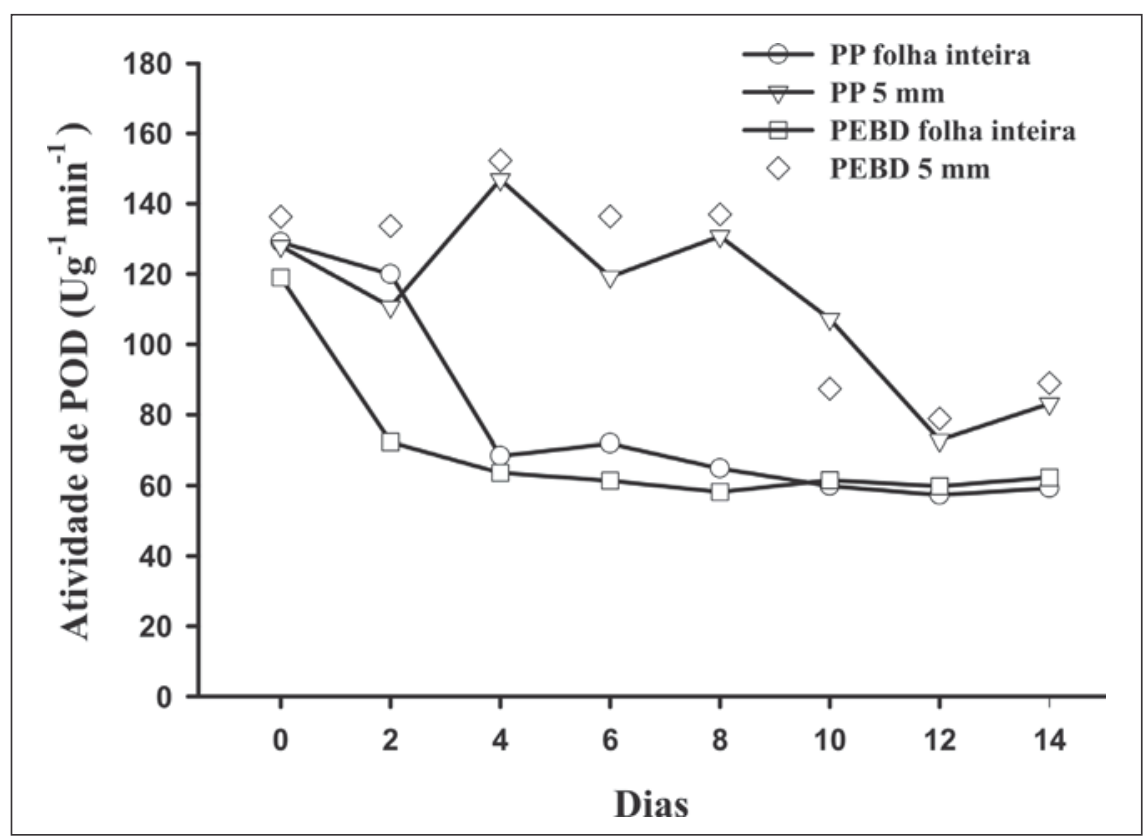

Figura 4. Atividade da peroxidase em alfaces minimamente processadas como folhas inteiras e tiras de $5 \mathrm{~mm}$, armazenadas a $5{ }^{\circ} \mathrm{C}$ em embalagens de PEBD e PP. Barras verticais representam \pm o desvio-padrão da média. $\mathrm{PEBD}=$ Polietileno de baixa densidade. $\mathrm{PP}=$ Polipropileno. $\mathrm{POD}=$ Peroxidase . Peroxidase activity of fresh-cut lettuce processed as whole leaves and $5 \mathrm{~mm}$ strips stored at $5{ }^{\circ} \mathrm{C}$ in LDPE and PP. Vertical bars represent \pm standard deviation. LDPE $=$ Low density polyethylene. $\mathrm{PP}=$ Polypropylene). Brasília, Embrapa Hortaliças, 2006.

duzido uma elevação na atividade da peroxidase logo após o processamento

mínimo. Entretanto, como esse estresse foi mais severo na alface minimamente 
processada na forma de tira, a atividade da enzima manteve-se elevada por mais tempo nesse tratamento, apresentando diminuição após 10 dias de armazenamento refrigerado.

Contrariamente ao observado para a atividade da polifenoloxidase (Figura 3), não se observaram diferenças significativas entre as atividades da enzima peroxidase nas diferentes embalagens utilizadas para o mesmo tipo de processamento mínimo (Figura 4).

O escurecimento enzimático é um dos fatores limitantes que afetam a vida de prateleira de frutas e hortaliças minimamente processadas (Brecht, 1995). Em diversos trabalhos, tem-se observado que os estresses mecânicos aumentam a atividade respiratória (Moretti et al., 1998), perda de água (Chuma et al., 1984), bem como podem alterar o sabor e o aroma (Moretti \& Sargent, 2000) e aumentar a atividade de enzimas relacionadas ao escurecimento enzimático (Ke \& Saltveit, 1989; Bower \& Van Lelyveld, 1985; Nicoli et al., 1994).

Os resultados obtidos no presente trabalho estão de acordo com Moretti et al. (2002) que observaram que o estresse mecânico causado pelo processamento mínimo aumentou a atividade metabólica de forma significativa de raízes de batata-doce minimamente processadas, com aumento do escurecimento enzimático nas raízes, sobretudo na cultivar Princesa.

O maior estresse sofrido pela alface crespa minimamente processada na forma de tiras de $5 \mathrm{~mm}$ ocasionou maior escurecimento enzimático e menores brilho e conteúdo de ácidos orgânicos, independentemente do tipo de sistema de embalagem empregado.

\section{REFERÊNCIAS}

AHVENAINEN R. 1996. New approaches in improving the shelf life of minimally processed fruit and vegetables. Trends Food Science Technology 7: 179-187.

AVENA-BUSTILLOS RJ; CISNEROSZEVALLOS LA; KROCHTAJM; SALTVEIT ME. 1993.Optimization of edible coatings on minimally processed carrots to reduce white blush using response surface methodology. Transactions of the American Society for Agricultural Engineering 36: 801-805.
BOWER JP; VAN LELYVELD LJ. 1985. The effects of stress history and container ventilation on avocado fruits polyphenol oxidase activity. Journal of Horticultural Science 60: 545-547.

BRECHT JK; SALTVEIT ME; TALCOTT SE; MORETTI CL. 2007. Alterações metabólicas. In: MORETTI CL (Ed.). Manual de Processamento Mínimo de Frutas e Hortaliças. Brasília: SEBRAE. p. 41-77.

BURNETTE FS. 1977. Peroxidase and its relationship to food flavor an quality: a review. Journal of Food Science 42: 1-5.

CANTWELL M. 1992. Postharvest handling systems, minimally processed fruits and vegetables. In: Postharvest technology of horticultural crops. KADER AA (Ed.). 2. ed. Davis: University California. Division of Horticultural and Natural Resources. p. 277281.

CANTWELL M. 2000. The dynamic fresh-cut sector of the horticultural industry. In: Encontro Nacional sobre Processamento de Frutas e Hortaliças, 2. Viçosa. Palestras...Viçosa: Universidade Federal de Viçosa, 2000. p.147-155.

CHITARRA MIF; CHITARRA AB. 2007. Processamento mínimo de alface. In: MORETTI CL (Ed.). Manual de Processamento Mínimo de Frutas e Hortaliças. Brasília: SEBRAE. p. 299-342.

CHUMA Y; MURATA S; IWAMOTO M; NISHIHARA A; HORI Y. 1984. Donner strawberry transportation in refrigerated truck for 700 kilometers. Annals of Agricultural Engineering Society 45: 292-297.

DEGL'INNOCENTI E; PARDOSSI A; TOGNONI F; GUIDI L. 2007. Physiological basis of sensitivity to enzymatic browning in 'lettuce', 'escarole' and 'rocket salad' when stored as fresh-cut products. Food Chemistry 104: 209-215.

FDA. Microbiological safety of controlled and modified atmosphere packaging of fresh and fresh-cut produce. 2001. 48 p. Disponível em: $<$ http://www.cfsan.fda.gov/ comm/ift36.html>. Acesso em: 02 maio 2003.

HEMEDA HM; KLEIN BP. 1990. Effects of naturally occuring antioxidants on peroxidase activity of vegetable extracts. Journal of Food Science 55: 184-186.

ISHII G; CALBO AG; SILVA JLO. 1993. Effect of mechanical injury on ripeness and quality of mature green tomatoes. Annual report from the department of applied plant physiology. Osaka: NIVOT. p. 78-9.

KADER AA. 1986. Biochemical and physiological basis for effects of controlled and modified atmospheres on fruits and vegetables. Food Technology 40: 99-104.

KE D; SALTVEIT ME. 1989. Plant hormone interaction and phenolic metabolism in the regulation of russet spotting in iceberg lettuce. Plant Physiology 88: 1136-1140.

KIM DM; SMITH NL; LEE CY.1994. Effect of heat treatment on firmness of apples and apple slices. Journal of Food Processing Preservation 18: 1-8.
KLEIN BP. 1987. Nutritional consequences of minimal processing of fruits and vegetables. Journal of Food Quality 10: 179-193.

LAMIKANRA O; WATSON MA. 2001. Effects of ascorbic acid on peroxidase and polyphenoloxidase activities in fresh-cut cantaloupe melon. Food Chemistry and Toxicology 66: 1283-1286.

McEVILY AJ; IYENGAR R. 1992. Inhibition of enzymatic browning in foods and beverages. Critical Review of Food Science Nutrition 32: 253-273.

MORETTI CL; SARGENT SA; HUBER DJ; CALBO AG; PUSCHMANN R. 1998. Chemical composition and physical properties of pericarp, locule and placental tissues of tomatoes with internal bruising. Journal of the American Society for Horticultural Science 123: 656-660.

MORETTI CL; SARGENT SA. 2000. Alteração de aroma e sabor em frutos de tomate com desordem fisiológica causada por impacto. Scientia Agrícola 57: 385-388.

MORETTI CL; ARAUJO AL; MAROUELLI WA; SILVA WLC. 2002. Respiratory activity and browning of minimally processed sweetpotatoes. Horticultura Brasileira 20: 497-500.

NICOLI MC; ANESE M; SEVERINI C. 1994. Combined effects in preventing enzymatic browning reactions in minimally processed fruit. Journal of Food Quality 17: 221-229.

PADIGLIA A; CRUCIANI E; PAZZAGLIA G; MEDDA R; FLORIS G. 1995. Purification and characterization of Opuntia peroxidase. Phytochemistry 38: 295-297.

PRIEPKE PE; WEI LS; NELSON AI. 1976. Refrigerated storage of prepackaged salad vegetables. Journal of Food Science 41: 379382.

PONCE AG; VALLE CE; ROURA SI. 2004. Natural essential oils as reducing agents of peroxidase activity in leafy vegetables. Lebensm.-Wiss. u.-Technology 37: 199-204.

ROLLE R; CHISM GW. 1987. Physiological consequences of minimally processed fruits and vegetables. Journal of Food Quality 10: 157-177.

SALTVEIT ME. 2000. Wound induced changes in phenolic metabolism and tissue browning are altered by heat shock. Postharvest Biology and Technology 21: 61-69.

SCHLIMME DV. 1995. Marketing lightly processed fruits and vegetables. HortScience 30: 15-17.

SHAMAILA M; POWRIE WD; SKURA BJ. 1992. Sensory evaluation of strawberry fruit stored under modified atmosphere packaging (MAP) by quantitative descriptive analysis. Journal of Food Science 57: 1168-1172.

VAMOS-VIGYAZO L. 1981. Polyphenoloxidase and peroxidase in fruits and vegetable. C.R.C. Critical Reviews in Food Science and Nutrition 15: 49-127.

VAUGHN KC; DUKE SO. 1984. Function of polyphenol oxidase in higher plants. Physiologia Plantarum 60: 106-112.

WILEY RC. 1994. Minimally processed refrigerated fruits and vegetables. London: Chapman \& Hall. 357 p. 